\title{
Cross reactivity between IA-2 and phogrin/IA-2 $\beta$ in binding of autoantibodies in IDDM
}

\author{
E.C.I. Hatfield, C.J. Hawkes, M. A. Payton, M. R. Christie \\ Department of Medicine, King's College School of Medicine and Dentistry, London, UK
}

\begin{abstract}
Summary Patients with insulin-dependent diabetes mellitus (IDDM) possess antibodies to the cytoplasmic domains of two closely related tyrosine phosphatase-like proteins, IA-2 and phogrin, previously detected as $40 \mathrm{kDa}$ and $37 \mathrm{kDa}$ tryptic fragments, respectively. A higher proportion of IDDM patients possess antibodies to IA- 2 than to phogrin, and autoimmunity to phogrin might arise through cross-reactivity with the highly homologous IA-2. In this study, we have investigated the major regions of IA2 recognized by antibodies in IDDM patients and examined the ability of phogrin to block antibody binding to these regions as a measure of cross-reactivity. Analysis of antibody binding to in vitro transcribed and translated polypeptides representing different regions of the cytoplasmic domain of IA-2 identified five different patterns of reactivity with antibodies in IDDM. Protein footprinting analysis, whereby polypeptide fragments generated on protease treatment
\end{abstract}

of immune complexes are studied, indicated considerable heterogeneity in antibody recognition of IA2 , even between sera with similar reactivity to deletion mutants. Blocking studies with recombinant phogrin indicated that IA-2 antibodies recognize epitopes that are both unique to IA- 2 and shared with phogrin. The amino-terminal 150 amino acids of the cytoplasmic domain of IA-2 encompass epitopes that are not represented on phogrin, whereas shared epitopes are localized within the carboxy-terminal 220 amino acids. The results demonstrate considerable heterogeneity between IDDM patients in autoantibody recognition of IA- 2 in IDDM, whereas antibody recognition of phogrin is restricted in most patients to epitopes also present on IA-2. [Diabetologia (1997) 40: $1327-1333]$

Keywords Autoantibodies, Autoantigens, Tyrosine phosphatase, Epitopes, Insulin-dependent diabetes.
Proteins originally detected as 40000 and $37000 \mathrm{M}_{\mathrm{r}}$ proteolytic fragments of $64000 \mathrm{M}_{\mathrm{r}}$ islet antigens $(40$ and $37 \mathrm{kDa}$-antigens) are major targets for antibodies in insulin-dependent diabetes (IDDM) [1,2] and the presence of autoantibodies to these antigens is highly

Received: 4 April 1997 and in revised form: 2 July 1997

Corresponding author: Dr. M.R. Christie, Department of Medicine, King's College School of Medicine and Dentistry, Bessemer Road, London SE5 9PJ, UK

Abbreviations: IDDM, insulin-dependent diabetes mellitus; PTP, protein tyrosine phosphatase; JM, juxtamembrane, Hepes, 4-(2-hydroxyethyl)-1-piperazine-ethanesulphonic acid; IA-2ic, cytoplasmic domain of IA-2; phogrin-ic, cytoplasmic domain of phogrin. predictive of disease development in a number of non-diabetic populations [3-5]. The 40 and $37 \mathrm{kDa}-$ antigens have been identified as two closely related proteins designated IA-2 (or ICA512) and phogrin (or IA-2 $\beta$ ), respectively [6-10]. Autoantibodies to both IA-2 and phogrin bind epitopes that are restricted to the cytoplasmic domain of these proteins [1012]. Regions within the cytoplasmic domain of IA-2 (amino acids 694-979) and phogrin (amino acids 716-1003) show close amino acid sequence similarities with each other $(88 \%)$, with the protein tyrosine phosphatase PTP1B (amino acids $1-295 ; 54 \%$ ) and other protein tyrosine phosphatases $[13,14]$. This region of the molecule may form a distinct tyrosine phosphatase (PTP)-like domain structure similar to that resolved for PTP1B [15]. The PTP domains are 


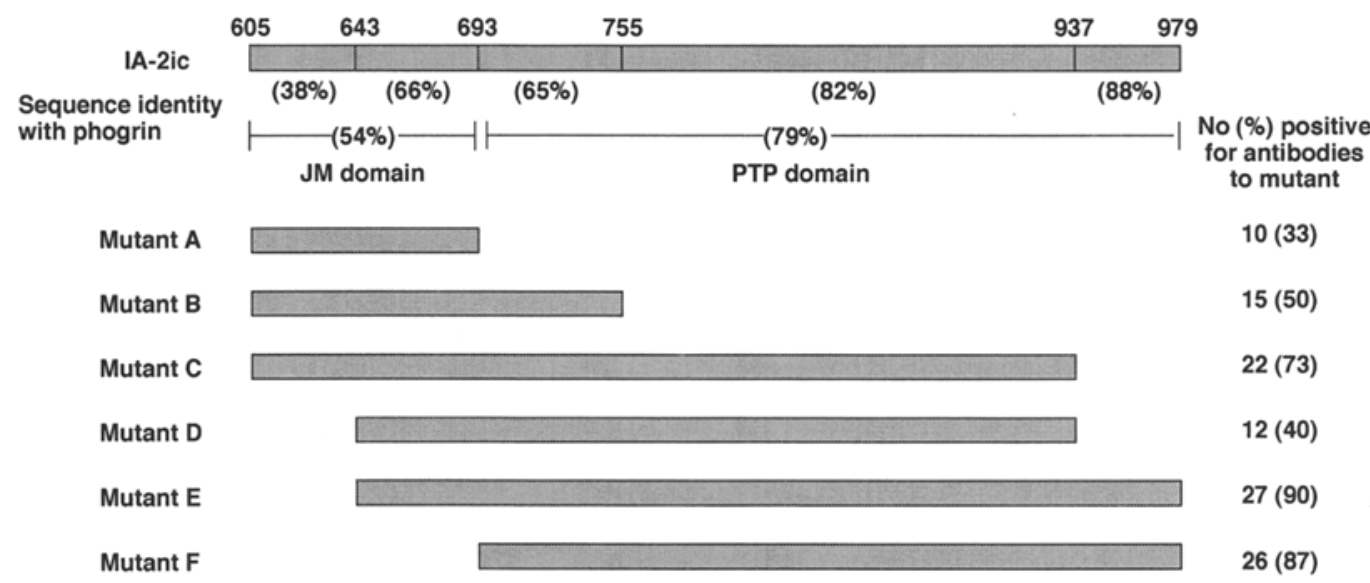

Fig.1. IA-2 constructs used in antibody analysis. Antibody reactivity to IA-2 was determined using in vitro transcribed and translated proteins representing the cytoplasmic domain (IA$2 \mathrm{ic})$ and a series of IA-2 mutants (A-F) having deletions in this region. The amino acid sequence identity of different regions of IA-2 with homologous regions of phogrin are indicated in the upper part of the Figure. The number and percentage of 30 IA-2 antibody positive IDDM patients that show reactivity with each deletion mutant is indicated on the right side of the Figure

linked to putative transmembrane domains that anchor the proteins to secretory granule membranes by a region (juxtamembrane domain) that shows weaker homology between IA-2 and phogrin (54\%).

Recent studies have shown that IA-2 is able to partially or completely block autoantibody binding to phogrin/IA-2 $\beta[6,9,10,16]$, suggesting that the two PTP-like proteins share epitopes for these antibodies. Use of deletion mutants has identified a number of distinct regions on IA-2 recognized by autoantibodies in IDDM $[11,12]$. These lie predominantly within the PTP domain but also, in a proportion of patients, within the juxtamembrane (JM) domain. An understanding of which regions of IA-2 and phogrin share cross-reactivity for antibodies in IDDM is important both to assess the importance of phogrin as an antigen in IDDM and in the design of screening assays for antibodies to these proteins. In this study we have further defined the regions on IA-2 that are recognized by antibodies in IDDM and have investigated which regions have epitopes that are cross-reactive with phogrin.

\section{Subjects and methods}

Subjects. Sera were obtained from IDDM patients from three different centres: i) from a multicentre study [17] in Sweden (disease duration < 1 month; age 1-14 years at onset, $n=60$ ); ii) from IDDM patients attending the Diabetes Clinic of King's College Hospital, London (disease duration
<6 months; age 6-31 years at onset, $n=20$ ); and iii) from patients attending the John Radcliffe Hospital, Oxford (disease duration $<3$ years; age 5-16 years at onset, $n=23$ ). All patients were analysed for antibodies to IA- 2 and phogrin as described below. A control reference population of 64 healthy subjects with no family history of IDDM was used to establish the normal range of antibodies to IA-2 and phogrin.

IA-2 and phogrin cDNA clones. cDNAs representing the cytoplasmic domain of human IA-2 (IA-2ic) and full length rat phogrin have been previously described $[6,14]$. cDNA representing the cytoplasmic region of phogrin (phogrin-ic; amino acids 632-1003) was prepared by DNA amplification using appropriate primers and ligated into the pSP64 poly A vector (Promega Corp, Madison, Wis., USA). IA-2ic and phogrin-ic cDNA was subcloned into the Pinpoint vector (Promega) for expression of recombinant protein as a fusion with a biotinylated purification tag.

Six deletion mutants of IA-2ic (Fig. 1), designated A (amino acids 605-693), B (amino acids 605-755), C (amino acids 605-937), D (amino acids 643-937), E (amino acids 643-979) and F (amino acids 693-979) were constructed by DNA amplification of IA-2ic cDNA using appropriate primer sequences. Amplification products were re-amplified with the same primer sequences but with additional sequences added at the 5' and 3 ' ends corresponding to restriction sites for BamHI and SacI (mutants B,C,D) or BamHI and SalI (mutants A,E,F). Re-amplification products were ligated into the appropriate restriction sites of the vector pGEM4Z (Promega). Nucleotide sequences of cloned products were verified by automated sequencing $(\mathrm{ABC}$, Charing Cross and Westminster Medical School, London, UK).

Antibody analysis. IA-2ic, phogrin-ic and IA-2 deletion mutant protein sequences were transcribed from specific cDNAs and translated in vitro in the presence of ${ }^{35} \mathrm{~S}$-methionine (Amersham International, Bucks, UK) in a single reaction using TNT-coupled reticulocyte lysate system (Promega). The sizes of translated proteins were confirmed as similar to those predicted from amino acid sequences by SDS-PAGE. Radioactivity incorporated into translated protein was determined by precipitation with $10 \%$ trichloroacetic acid and scintillation counting. Aliquots $(20 \mu \mathrm{l})$ containing $20000 \mathrm{cpm}$ of in vitro translated protein were incubated in immunoprecipitation buffer $(10 \mathrm{mmol} / \mathrm{l}$ Hepes, $\mathrm{pH} 7.4,150 \mathrm{mmol} / \mathrm{l} \mathrm{NaCl}, 20 \mathrm{mmol} / \mathrm{l}$ methionine, $0.5 \mathrm{mg} / \mathrm{ml}$ bovine serum albumin, $10 \mathrm{mmol} / \mathrm{l}$ Benzamidine and either $0.5 \%$ Triton X-100 or $0.1 \%$ Tween 20) with $5 \mu \mathrm{l}$ of test sera overnight at $4{ }^{\circ} \mathrm{C}$. Immune complexes were isolated on $5 \mu \mathrm{l}$ of protein A sepharose, and the immunoprecipitates washed extensively with immunoprecipitation 
buffer and subsequently with water, either by centrifugation or by vacuum filtration (Millipore Multiscreen Watford, Herts, UK). Radioactivity immunoprecipitated was determined by liquid scintillation counting and expressed as a percentage of that precipitated by a positive control serum included in each experiment. Sera were regarded as positive for antibodies to IA-2ic or phogrin-ic if antibody levels exceeded the mean plus 3 SD of antibody levels in 20 healthy control subjects. In studies with IA-2 deletion mutants, antibodies were considered to maintain strong binding to specific mutants if the antibody reactivity to the mutants exceeded $40 \%$ of that to the IA-2ic molecule. Sera were regarded to bind weakly to deletion mutants if reactivity was $10-40 \%$ of that to IA-2ic.

Blocking studies. Recombinant IA-2ic and phogrin-ic molecules were expressed in Escherichia coli as a fusion protein with a biotin labelled peptide sequence at the $\mathrm{N}$-terminus using the Pinpoint expression system. Bacteria were lysed by stirring with lysozyme $(1 \mathrm{mg} / \mathrm{ml})$ in $150 \mathrm{mmol} / 1 \mathrm{NaCl}, 10 \mathrm{mmol} / 1 \mathrm{He}$ pes, pH 7.4, followed by addition of Triton X-100 (0.1\%) for $5 \mathrm{~min}$ and DNase (200 units) for $15 \mathrm{~min}$. Cellular debris was sedimented by centrifugation at $10000 \mathrm{~g}$ for $10 \mathrm{~min}$. Recombinant IA-2ic or phogrin-ic was purified from lysates by passage through an avidin resin which had previously been equilibrated in buffer containing $150 \mathrm{mmol} / \mathrm{l} \mathrm{NaCl}$ and $10 \mathrm{mmol} / \mathrm{l} \mathrm{Hepes} \mathrm{pH}$ 7.4. The resin was washed thoroughly and the protein eluted with $5 \mathrm{mmol} / \mathrm{l}$ biotin. Biotin was removed from samples by dialysis. In blocking studies, sera were incubated with ${ }^{35} \mathrm{~S}-\mathrm{me}$ thionine labelled protein (IA-2ic, phogrin-ic or selected IA-2 deletion mutants) in the presence, or absence, of $5 \mu \mathrm{g}$ of purified unlabelled IA-2ic or phogrin-ic. Immune complexes were isolated on protein A sepharose and radioactivity immunoprecipitated determined as described above.

Analysis of antibody reactivity by protein footprinting studies. The ability of antibodies to protect IA-2 from proteolysis was analysed by protein footprinting [18]. Immune complexes were formed during incubation of IDDM patients' sera with in vitro transcribed and translated IA-2ic. After washing, these were treated with trypsin $(0.1 \mathrm{mg} / \mathrm{ml})$ at $30^{\circ} \mathrm{C}$ for $20 \mathrm{~min}$, and washed with water. Trypsin degradation products were subsequently analysed by SDS-PAGE and autoradiography as previously described [1].

\section{Results}

Prevalence of antibodies to IA-2 and phogrin. Sera from IDDM patients were screened for the presence of antibodies to the cytoplasmic domains of IA-2 and phogrin by radioligand binding assays using radiolabelled protein transcribed and translated in vitro from appropriate cDNAs. Sera were derived from 3 different centres: 60 patients with recent onset ( $<1$ month) IDDM from Sweden; 20 patients with short duration IDDM ( $<6$ months) from London; and 23 patients with longer duration IDDM ( $<3$ years) from Oxford. The frequencies of IA- 2 antibodies were 38 of $60(63 \%), 15$ of $20(75 \%)$, and 11 of $23(48 \%)$ in the Swedish, London and Oxford patients respectively. The corresponding frequencies of phogrin-antibodies were 29 of $60(48 \%), 9$ of 20 $(45 \%)$ and 8 of $23(35 \%)$. All except one of the phogrin-antibody positive patients were also positive for
A

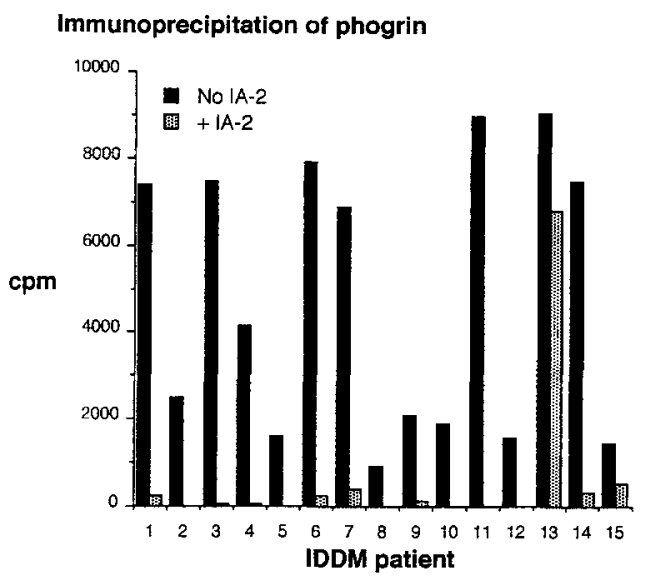

B

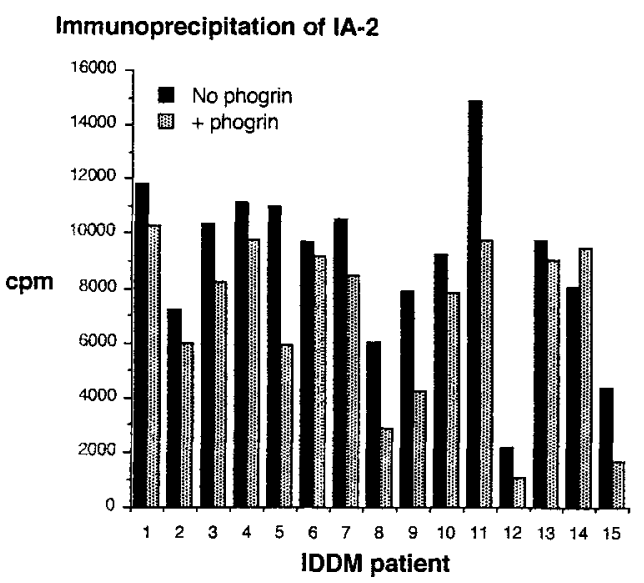

Fig.2A, B. Blocking studies of antibody binding to phogrin and IA-2. a) sera from 15 IDDM patients were incubated with ${ }^{35} \mathrm{~S}$-methionine labelled phogrin-ic in the absence $(\square)$ or presence (1) of $5 \mu \mathrm{g}$ of purified recombinant IA-2. Immunoprecipitates were isolated on protein A sepharose, washed and cpm immunoprecipitated determined by scintillation counting. b) The same sera were used to immunoprecipitate radiolabelled IA-2 in the presence or absence of recombinant phogrin

antibodies to IA-2 and there was a strong correlation between IA-2ic and phogrin-ic antibody levels in these patients $(r=0.74, p<0.001$; linear regression analysis). The antibody analysis identified 64 IA-2antibody positive and 46 phogrin-antibody positive patients for further characterization of antibody binding.

Blocking studies of antibody binding to IA-2 and phogrin. Experiments were performed to determine to what extent antibody reactivity to IA-2 or phogrin was influenced by the addition of an excess $(5 \mu \mathrm{g})$ of the other purified unlabelled PTP-like protein. Sera from 15 IDDM patients that were strongly positive for antibodies to both IA-2 and phogrin were selected for these experiments. The addition of unlabelled IA2 ic to immunoprecipitation reactions with radiolabelled phogrin effectively blocked antibody binding in most sera (Fig. 2a). In two samples (patients 13 and 
Table 1. Patterns of antibody binding to IA-2 deletion mutants. IDDM patients grouped according to the patterns of antibody reactivity with deletion mutants A-F. Positive binding to a deletion mutant is indicated by a " + ". The patterns of reactivity

\begin{tabular}{|c|c|c|c|c|c|c|c|c|c|}
\hline \multirow[t]{2}{*}{ Group } & \multicolumn{6}{|c|}{ Antibody binding to mutant } & \multirow{2}{*}{$\begin{array}{l}\text { No }(\%) \\
\text { in group }\end{array}$} & \multirow{2}{*}{$\begin{array}{l}\text { Region important in } \\
\text { antibody binding }\end{array}$} & \multirow{2}{*}{$\begin{array}{l}\text { No (\%) phogrin } \\
\text { antibody positive }\end{array}$} \\
\hline & $\overline{\mathrm{A}}$ & B & $\mathrm{C}$ & $\mathrm{D}$ & $\mathbf{E}$ & $\mathrm{F}$ & & & \\
\hline 1 & + & + & + & - & - & - & $2(7)$ & $605-643$ & $0(0)$ \\
\hline 3 & - & - & + & + & + & + & $5(17)$ & $755-937$ & $3(60)$ \\
\hline 4 & - & + & + & + & + & + & $7(23)$ & $693-755$ & $6(86)$ \\
\hline 5 & + & + & + & $+1-$ & + & + & $8(27)$ & $605-979$ & $8(100)$ \\
\hline
\end{tabular}

for each group of patients suggested the presence of multiple epitopes within the regions indicated as important in antibody binding
15, Fig. 2 a), IA-2ic inhibited antibody binding to phogrin-ic by less than $70 \%$. In contrast to these results, unlabelled phogrin-ic was ineffective at blocking antibody binding to radiolabelled IA-2 in most samples tested. In only 5 patients $[5,8,9,12$ and 15$]$ did phogrin-ic inhibition of antibody binding to IA-2ic exceed $45 \%$ (Fig. 2 b).

Analysis of binding to IA-2 deletion mutants. To further define antibody binding to IA-2, sera from the 64 IDDM patients identified as positive for antibodies to IA-2 were analysed for antibody reactivity to constructs representing the juxtamembrane (JM) and tyrosine phosphatase (PTP) domains of IA-2. Of these 64 patients, $17(27 \%)$ bound strongly to the JM construct and $59(92 \%)$ bound to the expressed PTP domain. Five of the sera (8\%) showed antibody reactivity only to the JM construct, $46(72 \%)$ only to the PTP domain and $13(20 \%)$ had antibodies to both. The 64 sera were also analysed for antibodies to the cytoplasmic domain of phogrin and $44(69 \%)$ of these were positive for these antibodies. All 5 sera having antibodies exclusively to the $\mathrm{JM}$ region were negative for antibodies to phogrin. In contrast, 33 $(72 \%)$ of the 46 patients with antibodies only to the IA-2 PTP domain and 11 ( $85 \%)$ of 13 sera with reactivity to both JM and PTP regions of IA-2 had antibodies to phogrin. Thus, epitopes that are cross-reactive between IA-2 and phogrin are likely to reside within the PTP domain rather than the poorly conserved JM region.

To further analyse regions within the PTP domain of IA-2 recognized by IDDM associated antibodies, 30 sera were selected at random from the 64 IA-2 antibody-positive patients ( 21 from the Swedish study, 6 from the London study and 3 from the Oxford study) for analysis of binding to IA-2 constructs with additional deletions within the cytoplasmic domain. These 30 sera had a similar distribution of antibody reactivity to the JM and PTP regions as the larger group: $2(7 \%)$ subjects reacting with the JM construct only, $20(67 \%)$ to PTP only and $8(27 \%)$ to both JM and PTP regions. The numbers and proportions of patients positive for each deletion mutant are shown in Figure 1 . Ten (33\%) of the 30 IA-2 antibody positive patients were positive for antibodies to the JM region (mutant A) and $15(50 \%)$ to a molecule extended to residue 755 within the PTP domain (mutant B). Approximately $90 \%$ of patients remained positive after deletion of the JM domain (mutant F), or the first 38 amino acids of this region (mutant $E$ ) and $73 \%$ of patients were positive to a mutant with the C-terminal 42 amino acids deleted (mutant $\mathrm{C}$ ). However, only $40 \%$ of IA-2 antibody-positive patients still bound a mutant with deletions to both N-terminal and C-terminal parts of IA-2ic. Thus, the integrity of the extreme C- or N-terminal portions of the IA-2 cytoplasmic domain are critical for antibody recognition for most IDDM patients.

The 30 patients with IA-2 antibodies could be grouped according to the pattern of antibody recognition of each of the 6 deletion mutants (Table 1). The two sera with JM-specific antibodies (group 1) each bound strongly to the 3 mutants containing the JM domain (mutants A-C), but were negative, or bound only weakly, mutants lacking amino acid residues 605-643 (mutants D,E). These results are consistent with JM epitopes requiring residues predominantly within the first 38 amino acids of the cytoplasmic region of the molecule. Of the 20 sera with antibodies which did not bind strongly to the JM construct (mutant A), 8 also failed to bind mutants B,C and D, but bound strongly to mutants $\mathrm{E}$ and $\mathrm{F}$, indicating that the carboxy-terminal 42 amino acids are essential for antibody reactivity (group 2). Of these 8 sera, 5 $(63 \%)$ were positive for phogrin antibodies. Seven of the JM antibody-negative sera bound to mutant B representing amino acids 605-755 (group 4), indicating that specific epitopes reside within the region 693-755 of the protein. Six of these were phogrin antibody-positive. The remaining $5 \mathrm{JM}$ antibody-negative sera were negative for the 605-755 mutant, but positive for mutants $C, D, E$ and $F$, suggesting that antibody recognition for these sera is predominantly within the central part of the cytoplasmic domain (group 3). Three of these $5(60 \%)$ were positive for phogrin antibodies.

Eight sera (27\%) had antibodies that immunoprecipitated both the JM and PTP constructs, as well as most of the other mutants, suggestive of widespread 


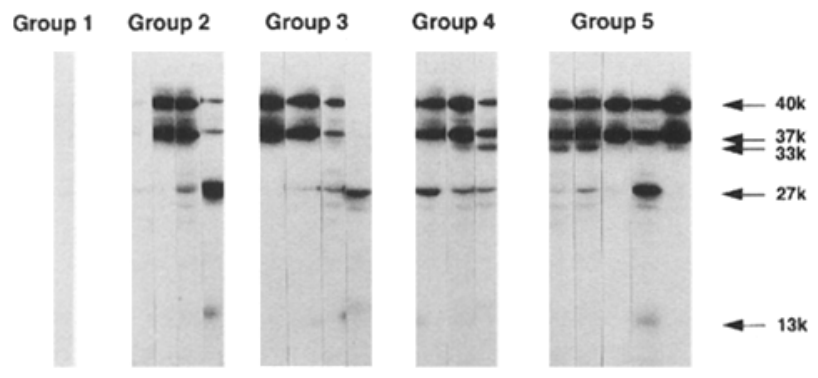

Fig. 3. Protein footprinting analysis of antibody binding to IA2. Sera from IDDM patients were used to immunoprecipitate IA-2ic and immune complexes were treated with trypsin before analysis of peptide fragments generated. Examples of protein footprinting patterns obtained from patients grouped according to their reactivity with deletion mutants (see Table 1) are illustrated. The $M_{r}$ of the major fragments generated are indicated on the right side of the Figure

antibody recognition of multiple epitopes localised throughout the entire cytoplasmic domain of IA-2 (group 5). All were positive for phogrin antibodies. Six of these bound poorly to the 643-937 construct indicating that either the C-terminal or N-terminal 40 amino acids are necessary for antibody recognition.

Analysis of antibody binding by protein footprinting. Antibody reactivity to IA-2ic in the same 30 patients was also analysed by protein footprinting, where the ability of antibodies to protect proteolytic cleavage by specific proteases is studied. Immune complexes formed between autoantibodies and in vitro transcribed and translated IA-2ic were treated with trypsin before analysis of tryptic fragments formed by SDS-PAGE and autoradiography. Different protein footprinting patterns were obtained with different sera, confirming the results of the deletion mutant studies showing heterogeneity between patients in regions on IA-2 recognized (Fig. 3). Protein footprints were compared within groups of patients having similar reactivity with the deletion mutants, as defined in Table 1 , to determine whether common patterns of fragments within groups could be identified (Fig.3). Immune complexes for all Group 1 sera were highly sensitive to trypsin treatment and only gave weak bands on the footprint. However, within other groups there were differences in the protein footprints obtained, indicating that there is heterogeneity in antibody recognition of IA-2, even within the specific regions of the molecule defined by reactivity with deletion mutants.

Blocking of antibody binding to IA-2 deletion mutants. Studies described above indicated that phogrin was relatively ineffective at blocking antibody binding to the cytoplasmic domain of IA-2. However, blocking studies with restricted regions of the molecule represented by the IA- 2 deletion mutants might

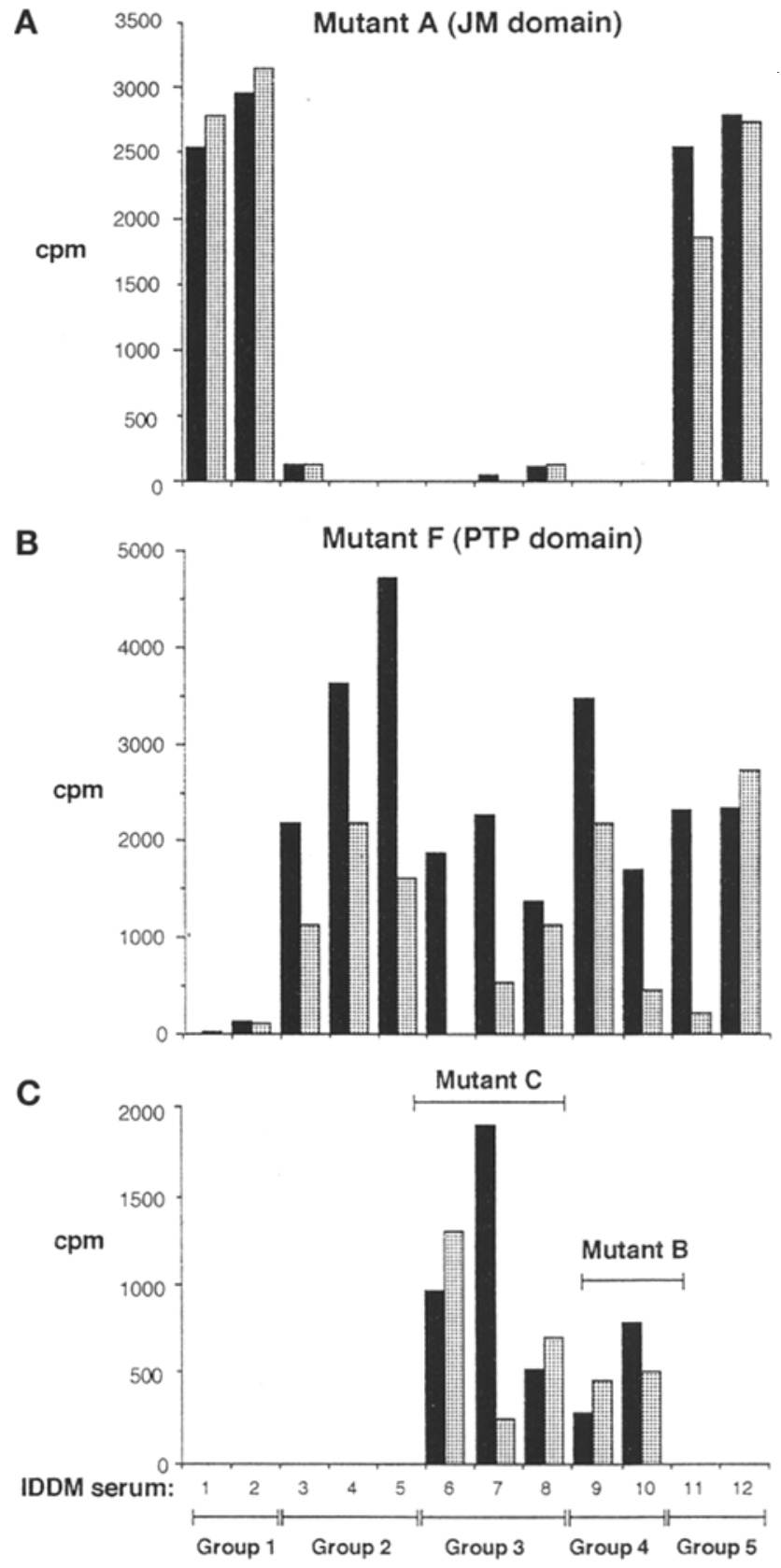

Fig.4. Blocking studies with IA-2 deletion mutants. Sera from 12 IDDM patients were used to immunoprecipitate IA-2 deletion mutants A, F, C or B in the absence ( $\mathrm{O}$ ) or presence (桶) of $5 \mu \mathrm{g}$ of purified recombinant phogrin. Radioactivity immunoprecipitated was determined as described in the legend of Figure 2

identify specific regions on IA-2 that have cross-reactivity with phogrin. Therefore, the ability of purified recombinant phogrin-ic to block antibody binding to radiolabelled in vitro transcribed and translated IA2 deletion mutants was investigated. Sera containing antibodies representative of different patterns of IA2 reactivity described above were selected for this analysis. Phogrin failed to block antibody binding to mutant A (Fig.4a), representing the JM domain, 
indicating that this region contains epitopes that are unique to IA-2. Similarly, phogrin did not block antibody binding to mutant $\mathrm{B}$ (Fig. $4 \mathrm{c}$ ), using sera negative for antibodies to the JM domain, suggesting that the region of IA-2 encompassing amino acids 693755 also contains epitopes not represented on phogrin. Analysis of antibody binding to the PTP domain of IA-2 (amino acids 693-979; Fig. 4b) showed variable degrees of blocking by phogrin. Of 10 sera analysed that were positive for antibodies to this region, 6 showed a more than $45 \%$ reduction in antibody binding in the presence of recombinant phogrin. However, with most sera, blocking was incomplete, indicating that both unique and shared epitopes are represented within the PTP domain. Similar results were obtained with mutant $\mathrm{C}$, representing amino acids 605-937 (Fig. 4c).

\section{Discussion}

Two distinct, but homologous, PTP-like proteins IA-2 and phogrin are major targets for autoantibodies associated with IDDM, but it is currently unclear whether immune responses to these proteins develop independently, or whether antibody recognition of one PTP is merely a consequence of the close amino acid sequence homology with the other. The results of this study indicate that IA-2 is the dominant PTPlike protein in IDDM, and that a considerable portion of antibody binding to phogrin can be explained by the presence of cross-reactive epitopes on the two proteins. Thus, a higher proportion of recent-onset IDDM patients have antibodies to IA-2 than to phogrin, and the addition of purified IA-2 was able to completely block antibody binding to phogrin in many patients; in contrast, phogrin was relatively ineffective at blocking antibody reactivity to IA-2. These results suggest that antibody reactivity to IA-2 is directed to a more diverse range of epitopes than for antibodies to phogrin, which, in most cases, binds epitopes present on both PTP-like proteins.

The heterogeneity in epitopes on IA-2 recognized by antibodies in IDDM is confirmed by analysis of antibody binding to IA-2 deletion mutants, and by protein footprinting techniques. The deletion mutant studies identify at least 4 distinct regions on IA-2 important for recognition by autoantibodies that span the entire cytoplasmic domain of the molecule. Thus, the majority of IDDM patients possess antibodies directed to the PTP domain, and the integrity of the extreme C-terminal 42 amino acids (937-979) of the protein is critical for antibody binding in more than one quarter of IA-2 antibody-positive patients. One third of IA-2 antibody-positive patients also have antibody reactivity to the first 38 amino acids of the juxtamembrane domain (605-643) and in a proportion of these patients, antibody reactivity is directed exclusively to this domain (Group 1, Table 1). Other antibody epitopes reside within the region of IA-2 represented by amino acids 755-937. Our data are largely in accord with previously published studies with different sets of IA-2 deletion mutants $[11,12]$ and extend these studies to identify a specific region within the PTP domain (amino acids 693-755) containing major epitopes for IA-2 antibodies in at least $23 \%$ of patients (Group 4, Table 1). Analysis of the ability of autoantibodies to protect regions of IA-2 from proteolysis, demonstrated that patients who had similar antibody reactivity to IA-2 deletion mutants had different protein footprinting patterns, indicating that even within the regions identified as important for antibody reactivity by deletion mutant analysis, there is considerable heterogeneity in epitopes recognized.

Further blocking studies performed with recombinant phogrin against the IA-2 deletion mutants identified specific regions within IA-2 that encompass epitopes unique to IA-2. Phogrin was unable to block antibody binding to mutant $\mathrm{A}$, representing the JM region of IA-2, or to mutant $B$ (amino acids 605$755)$ in patients negative for antibodies to the JM region (605-693). Thus, autoantibody epitopes within the JM domain, and within amino acids 693-755, show little cross-reactivity with phogrin. As might be expected, these are the regions showing lowest amino acid identity between IA-2 and phogrin (see Fig. 1). Experiments performed with mutants $F$ and $C$ showed variability in the effectiveness of phogrin to block antibody binding to these constructs. The carboxyl terminal portion of IA-2, that shows a high degree of homology with phogrin, possesses epitopes that are both unique and are shared with phogrin. This study was unable to identify any single dominant region of cross-reactivity between the two proteins.

In the majority of IDDM patients, epitopes for phogrin antibodies appear to be shared with IA-2. However, in a small proportion of these patients, IA2 does not completely block antibody binding to phogrin. Similar results have been reported in other studies $[9,16]$. A proportion of IDDM patients therefore have evidence of a specific immune response to phogrin. Furthermore, one IDDM patient in this study, and several patients in other studies $[9,16]$, were positive for antibodies to phogrin/IA- $2 \beta$ in the absence of IA-2 antibodies. We have also recently identified additional non-diabetic individuals with polyendocrine autoimmunity who are IA-2 antibody negative, but strongly positive for phogrin antibodies [19]. These results indicate that immune responses to phogrin can be sustained independently of an immune response to IA-2. Further characterization of the properties of IA-2 and phogrin, including analysis of the sites and regulation of protein expression, may shed light on why IA-2 is the dominant IA-2-like protein in IDDM and under what circumstances an independent immune response to phogrin is elicited. 
Acknowledgements. This study was supported by grants from the Wellcome Trust and the Juvenile Diabetes Foundation International. E.C.I.H. is supported by a Wellcome Trust Research Training Fellowship, C.J.H. by a Medical Research Council Studentship. M.R.C. is a Royal Society University Research Fellow.

\section{References}

1. Christie M, Vohra G, Champagne P, Daneman D, Delovitch TL (1990) Distinct antibody specificities to a 64-kD islet cell antigen in type 1 diabetes as revealed by trypsin treatment. J Exp Med 172: 789-794

2. Christie MR, Hollands JA, Brown TJ, Michelsen BK, Delovitch TL (1993) Detection of pancreatic islet $64,000 \mathrm{Mr}$ autoantigens in insulin-dependent diabetes distinct from glutamate decarboxylase. J Clin Invest 92: 240-248

3. Christie MR, Genovese S, Cassidy D et al. (1994) Antibodies to islet $37 \mathrm{k}$-antigen, but not to glutamate decarboxylase, discriminate rapid progression to insulin-dependent diabetes mellitus in endocrine autoimmunity. Diabetes 43: 1254-1259

4. Bingley PJ, Christie MR, Bonifacio E et al. (1994) Combined analysis of autoantibodies improves prediction of IDDM in islet cell antibody-positive relatives. Diabetes 43: $1304-1310$

5. Genovese S, Bingley PJ, Bonifacio E et al. (1994) Combined analysis of IDDM-related autoantibodies in healthy schoolchildren. Lancet 344: 756

6. Payton MA, Hawkes CJ, Christie MR (1995) Relationship of the 37,000 - and $40,000-\mathrm{M}_{\mathrm{r}}$ tryptic fragments of islet antigens in insulin-dependent diabetes to the protein tyrosine phosphatase-like molecule IA-2 (ICA512). J Clin Invest 96:1506-1511

7. Bonifacio E, Lampasona V, Genovese S, Ferrari M, Bosi E (1995) Identification of protein tyrosine phosphatase-like IA-2 (islet cell antigen 512) as the insulin-dependent diabetes-related $37 / 40 \mathrm{k}$ autoantigen and a target of islet cell antibodies. J Immunol 155: 5419-5426

8. Passini N, Larigan JD, Genovese S, Appella E, Sinigaglia F, Rogge L (1995) The 37/40-kilodalton autoantigen in insulin-dependent diabetes mellitus is the putative tyrosine phosphatase IA-2. Proc Natl Acad Sci 92: 9412-9416
9. Lu J, Li Q, Xie $\mathrm{H}$ et al. (1996) Identification of a second transmembrane protein tyrosine phosphatase, IA-2beta, as an autoantigen in insulin-dependent diabetes mellitus: precursor of the 37-kDa tryptic fragment. Proc Natl Acad Sci 93: 2307-2311

10. Hawkes CJ, Wasmeier C, Christie MR, Hutton JC (1996) Identification of the $37-\mathrm{kDa}$ antigen in IDDM as a tyrosine phosphatase-like protein (phogrin) related to IA-2. Diabetes 45: $1187-1192$

11. Lampasona V, Bearzatto M, Genovese S, Bosi E, Ferrari M, Bonifacio E (1996) Autoantibodies in insulin-dependent diabetes recognize distinct cytoplasmic domains of the protein tyrosine phosphatase-like IA-2 autoantigen. J Immunol 157: 2707-2711

12. Zhang B, Lan MS, Notkins AL (1997) Autoantibodies to IA-2 in IDDM location of major antigenic determinants. Diabetes 46: 40-43

13. Lan MS, Lu J, Goto Y, Notkins AL (1994) Molecular cloning and identification of a receptor-type protein tyrosine phosphatase, IA-2, from human insulinoma. DNA Cell Biol 13: 505-514

14. Wasmeier C, Hutton JC (1996) Molecular cloning of phogrin, a protein-tyrosine phosphatase homologue localized to insulin secretory granule membranes. J Biol Chem 271: $18161-18170$

15. Barford D, Flint AJ, Tonks NK (1994) Crystal structure of human protein tyrosine phosphatase 1B. Science 263: 1397-1404

16. Kawasaki E, Eisenbarth GS, Wasmeier C, Hutton JC (1996) Autoantibodies to protein tyrosine phosphataselike proteins in type I diabetes: overlapping specificities to phóogrin and ICA512/IA-2. Diabetes 45: 1344-1349

17. Christie $M$, Landin Olsson $M$, Sundkvist $G$, Dahlquist $G$, Lernmark A, Baekkeskov S (1988) Antibodies to a Mr64000 islet cell protein in Swedish children with newly diagnosed type 1 (insulin-dependent) diabetes. Diabetologia 31: 597-602

18. Shesberadaran H, Payne L (1988) Protein antigen-monoclonal antibody contact sites investigates by limited proteolysis of monoclonal antibody-bound antigen: protein "footprinting". Proc Natl Acad Sci 85: 1-5

19. Lai M, Christie M, Betterle C, Foxon R, Zanchetta R, Spadaccino A, Bottazzo GF (1997) "The UK and Padua polyendocrine prospective study". Association of antibodies to IA-2 and phogrin and progression to IDDM. Diabetologia 40 [Suppl 1] 40:A76 (Abstract) 